\title{
Improvement of a face perception deficit via subsensory galvanic vestibular stimulation
}

\section{Citation}

Wilkinson, David, Philip Ko, Patrick Kilduff, Regina McGLINCHEY, and William Milberg. 2005. "Improvement of a Face Perception Deficit via Subsensory Galvanic Vestibular Stimulation." Journal of the International Neuropsychological Society 11 (07). doi:10.1017/ S1355617705051076.

\section{Permanent link}

http://nrs.harvard.edu/urn-3:HUL.InstRepos:41543037

\section{Terms of Use}

This article was downloaded from Harvard University's DASH repository, and is made available under the terms and conditions applicable to Other Posted Material, as set forth at http:// nrs.harvard.edu/urn-3:HUL.InstRepos:dash.current.terms-of-use\#LAA

\section{Share Your Story}

The Harvard community has made this article openly available. Please share how this access benefits you. Submit a story.

Accessibility 


\title{
BRIEF COMMUNICATION
}

\section{Improvement of a face perception deficit via subsensory galvanic vestibular stimulation}

\author{
DAVID WILKINSON, PHILIP KO, PATRICK KILDUFF, REGINA MCGLINCHEY, \\ AND WILLIAM MILBERG \\ Geriatric Neuropsychology Laboratory, New England Geriatric Research, Education \& Clinical Center, Veterans Affairs, \\ Boston Medical Center and Department of Psychiatry, Harvard Medical School, Boston, Massachusetts
}

(Received June 7, 2005; Final Revision August 30, 2005; Accepted September 1, 2005)

\begin{abstract}
The remediative effect of galvanic vestibular stimulation (GVS) was investigated in a patient who, following right hemisphere damage, is profoundly unable to recognize faces. We administered a two-alternative forced choice match-to-sample task in which the patient had to choose which of two faces matched a sample face presented directly above, while bipolar, transcutaneous current was applied to the left and right vestibular nerves at a level below the patient's sensory threshold. Performance improved beyond the chance-level observed prestimulation, and relied on reversing the electrode polarity across two separate blocks of trials, such that each mastoid received positive current for one block and then negative charge for the next. Although our study involved only a single case, the data provide preliminary evidence that a deficit in perceptual face matching can be reduced by GVS. This raises the intriguing possibility that other unilateral visual disorders may also respond in such a manner. (JINS, 2005, 11, 925-929.)
\end{abstract}

Keywords: Face processing, Vision, Prosopagnosia, Stroke, Sensory stimulation, Rehabilitation

\section{INTRODUCTION}

Patients with damage to ventral, posterior parts of the brain are especially prone to deficits in face perception (Bodamer, 1947). Although there is no effective treatment, there is a growing consensus that some acquired unilateral disorders may respond to peripheral nerve stimulation (Volpe et al., 2000; Kimberley et al., 2004). For example, stimulation of the vestibular nerves can temporarily ameliorate the symptoms of visuo-spatial neglect, a disorder in which the sufferer fails to respond to visual stimuli falling on the contralesional side of space (Vallar et al., 1997). Given that disorders of face processing can also arise after unilateral damage (De Renzi et al., 1994), and that the cortical areas associated with face stimuli are strongly activated by vestibular stimulation (Bense et al., 2001), it seemed possible that the method might also restore aspects of face perception.

Reprint requests to: David Wilkinson, Department of Psychology, Keynes College, University of Kent, Canterbury, Kent, CT2 7NP, UK.
Vestibular input can be manipulated via either caloric or optokinetic stimulation (see Kerkhoff, 2003). However, these forms of stimulation induce nystagmus and distraction and do not translate well to the clinical setting. One procedure that overcomes these shortcomings is galvanic vestibular stimulation (GVS). An additional benefit is that electric current can be applied at extremely low levels that are undetectable to the patient. GVS involves the delivery of transcutaneous currents to the mastoid bones, which in turn modulate underlying vestibular outputs from the semicircular canals and otoliths (Coats, 1972). These outputs project via the eighth cranial nerve to nuclei in the pons and medulla, which indirectly feed a large cortical network that is distributed mainly across the parietal and temporal lobes. Neurons in this network are both bi-modal (i.e., vestibularvisual) and purely visual, and seem important for visuospatial analysis and ocular-motor control (Bense et al., 2001). The idea is that vestibular stimulation can induce corrective changes in these cortical regions by boosting activity in either damaged or intact compensatory circuits (see Robertson \& Murre, 1999). In line with this, a recent study 


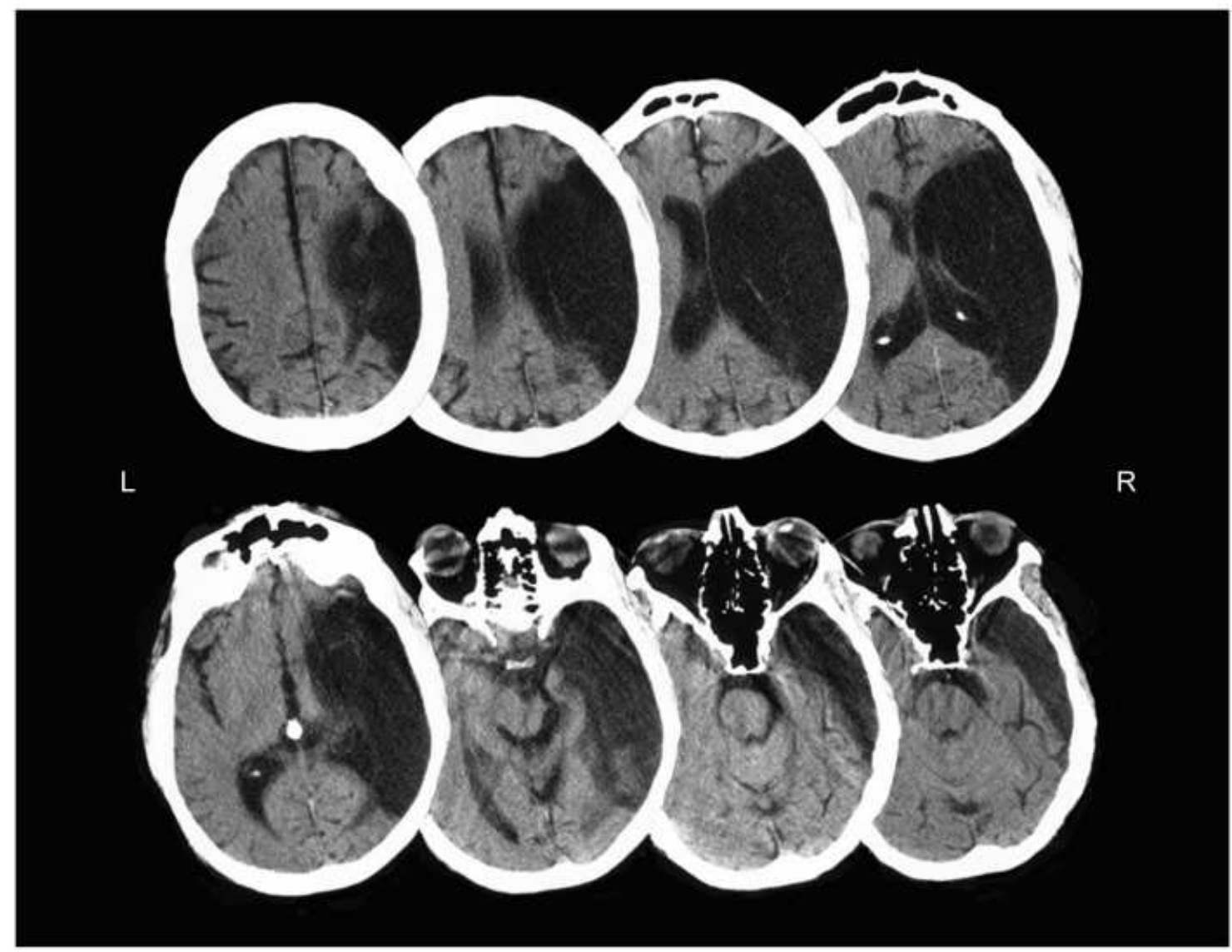

Fig. 1. Patient computed tomagraphy (CT) scan shown upward from the level of inferior temporal gyrus. The left and right sides of the brain are labeled with $\mathrm{L}$ and $\mathrm{R}$, respectively.

reported temporary remediation of visual neglect in fourteen, acute stroke patients (Rorsman et al., 1999). However, there has been no attempt to extend this finding to other kinds of patients, so it remains unclear if the effects of GVS are specific to the mechanics of neglect.

\section{METHOD}

The patient R.C. endured an embolic infarct of the right middle cerebral artery in 1983 that rendered him unable to recognize close relatives by facial appearance, or perform standard face recognition tests above chance. See Figure 1 and Table 1 for further details.

To examine the effects of GVS on face perception, we administered a simultaneous match-to-sample task, in which two horizontally aligned faces appeared directly below a sample face. On each trial, one face was identical to the sample while the eyes and mouth of the other were inverted. The patient pressed one of two buttons (marked "left" and "right") with the index and middle finger of his right hand, respectively, to indicate the match. Ten digitized gray-scale images of male faces were selected from the face database provided by the Max-Planck Institute for Biological Cybernetics, Tuebingen, Germany. The target appeared equally often in the left and right position but varied randomly across trials. Stimuli appeared on an opaque background for $3500 \mathrm{~ms}$, after which there was a blank screen lasting until an unspeeded response was made. Each intact face served twice as the sample image generating a total of 20 trials, and the order of presentation was randomized across experiments.

Bipolar, direct current was delivered via a stimulus isolator to a pair of $3-\mathrm{cm}^{2}$ carbon-rubber, self-adhesive, electrodes that were placed over the right and left mastoid processes. ${ }^{a}$ Sensory threshold was established using a staircase procedure that moved from 0 in 0.1 -milliamp ( $\mathrm{mA}$ ) increments until localized tingling was felt at the electrode sites. Threshold was then confirmed by adjusting the current down by $0.3 \mathrm{~mA}$ and staircasing up until tingling was once again felt. The current was then set at $90 \%(1.2 \mathrm{~mA}$ in all experiments) of this estimate. R.C. was informed that he would receive stimulation on some, but not all, blocks of trials. The patient was asked at the start and finish of each block if he had felt any unusual sensation behind the ears, and was also asked if he had at any time felt disoriented or

${ }^{a}$ Ethical approval was obtained from the Boston VA Healthcare System IRB, and the patient provided written informed consent to participate. 
Table 1. Demographic, anatomical, and behavioral data of patient R.C.

\begin{tabular}{|c|c|}
\hline \multicolumn{2}{|l|}{ Demographic information } \\
\hline Age & 61 \\
\hline Handedness & Right \\
\hline Years poststroke & 22 \\
\hline Years of education & 17 \\
\hline Lesion distribution & $\begin{array}{l}\text { All of right temporal lobe, right inferior frontal gyrus, } \\
\text { right basal ganglia, right thalamus, lower } 2 / 3 \text { rds of right } \\
\text { premotor and motor areas, right superior parietal lobe } \\
\text { extending to all of the supramarginal and angular gyri }\end{array}$ \\
\hline \multicolumn{2}{|l|}{$\begin{array}{l}\text { Standard visual test performance prior to } \\
\text { stimulation }(\% \text { correct) }\end{array}$} \\
\hline \multicolumn{2}{|l|}{ Faces } \\
\hline Benton Facial Recognition Test (long form) & $15 \%$ (1st percentile) \\
\hline Wechsler Memory Scale Immediate Test for Faces & $48 \%$ (5th percentile) \\
\hline \multicolumn{2}{|l|}{ Famous Faces from: } \\
\hline Last 20 years & $15 \%$ (5th percentile) \\
\hline Last 40 years & $15 \%$ (5th percentile) \\
\hline \multicolumn{2}{|l|}{ Non-faces } \\
\hline Boston Naming Test & $93 \% *$ \\
\hline \multicolumn{2}{|l|}{ Birmingham Object Recognition Battery } \\
\hline \multicolumn{2}{|l|}{ Feature matching: } \\
\hline Lengths of adjacent lines & $87 \% *$ \\
\hline Sizes of adjacent circles & $90 \% *$ \\
\hline Orientation of adjacent lines & $80 \% *$ \\
\hline Gap positions in adjacent circles & $93 \% *$ \\
\hline \multicolumn{2}{|l|}{ Object constancy $^{1}$ : } \\
\hline Foreshortened view ${ }^{a}$ & $92 \% *$ \\
\hline Minimal feature match ${ }^{\mathrm{b}}$ & $88 \% *$ \\
\hline \multicolumn{2}{|l|}{ Access to stored knowledge ${ }^{2}$} \\
\hline Easy version & $88 \% *$ \\
\hline Hard version & $72 \% *$ \\
\hline
\end{tabular}

\footnotetext{
* = Within normal limits.

${ }^{1}$ On each trial the patient had to decide which two of the three pictures presented belonged to the same object. One of the pictures was taken from a standard view, one was a visually similar object, and the other was the same object as the first but with: athe main identifying feature evident but overall shape occluded, or ${ }^{b}$ the main identifying feature occluded but overall shape evident.

${ }^{2}$ Individual pictures of objects (animals or tools) had to be classified as either real or nonreal.
}

dizzy. No such effects were reported, although we note that in future studies it will be useful to supplement these verbal reports with more objective tests of subliminal perception. To vary the presence and side (left, right) of stimulation, we administered the task across four experimental sessions.

\section{RESULTS}

To assess whether improvement had occurred, we first established the patient's baseline level of accuracy prior to stimulation. His accuracy on the face-matching task was $40 \%$ which is within 1 standard error (SE) of chance (50\%) for a binomial distribution based on twenty observations. ${ }^{\text {b }}$ We therefore tested performance against the criterion of $50 \%$,

${ }^{\mathrm{b}} S E=\sqrt{p q / n}$, where $p$ and $q=$ the expected proportion of correct $(0.5)$ and incorrect $(0.5)$ responses, and $n=$ number of observations (20). At a $p$ value of .05 , one standard error $(S E)$ from the absolute chance level of $50 \%$ corresponds with $39 \%$ and $61 \%$. which we note is in fact more conservative than using $40 \%$, as there is a reduced likelihood of finding significant improvement. To provide a broader gauge of task difficulty, we also tested a control group (without stimulation) that consisted of eleven, age-matched (mean age of 61), healthy individuals. The control group produced a mean level of accuracy of $96 \%$ with a standard deviation of 8 (this $S D$ was inflated by the data from one subject who performed at $72 \%$ accuracy-all others performed above 95\%). In the experiments reported next, there was no instance in which R.C.'s level of accuracy fell within two standard deviations of this group mean.

In Experiment 1, stimulation was first administered with the anode and cathode positioned on the left and right mastoids, respectively. This was associated with a response accuracy of $50 \%$ (see Fig. 2). After a 15-min break, we switched the positions of the electrodes and observed a $25 \%$ significant increase in accuracy, $t(19)=2.9, p<.01$. To assess whether improvement was dependent on the direction of 


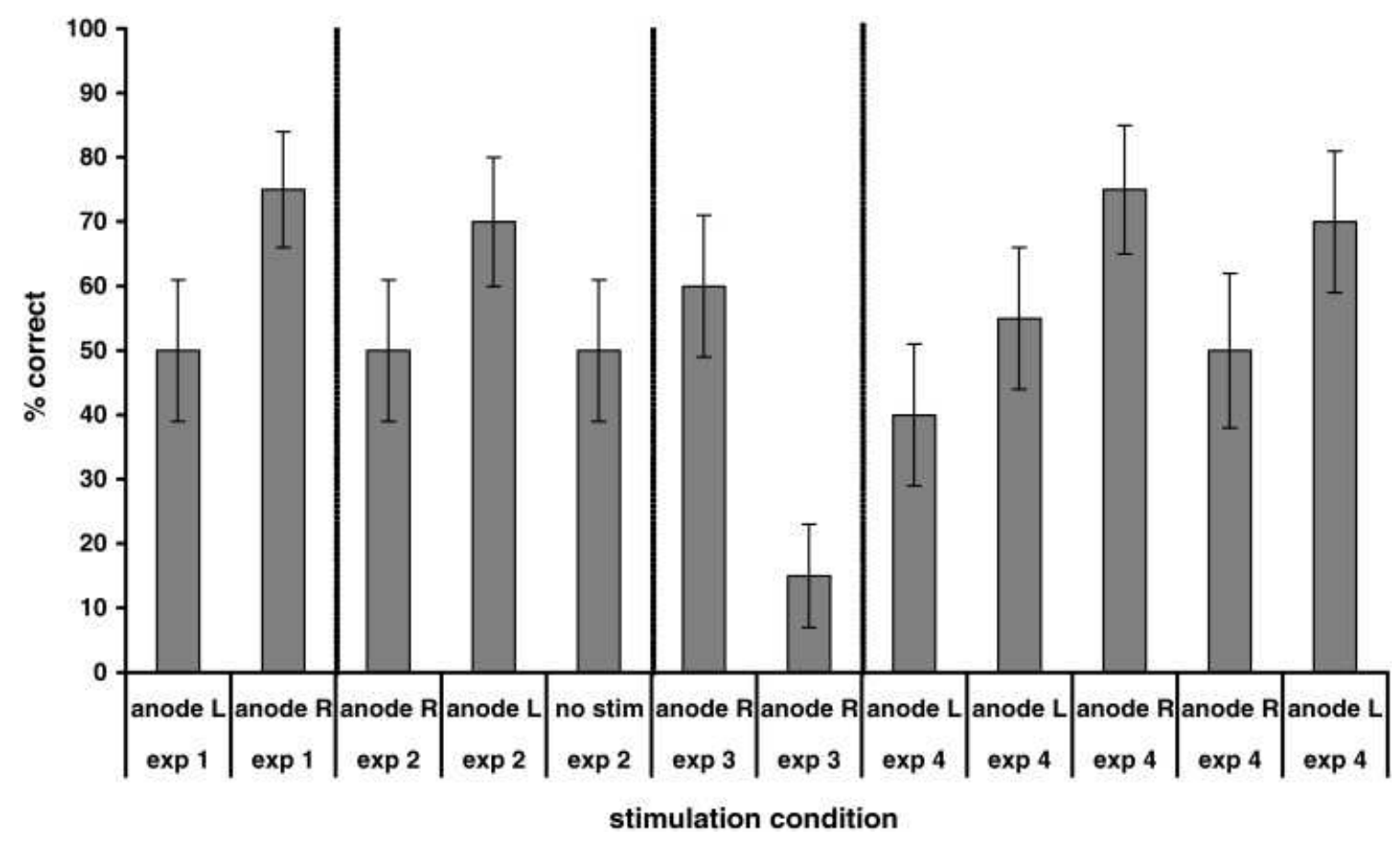

Fig. 2. Response accuracy (with standard deviation bars) as a function of stimulation condition. All blocks of trials were separated by a 15 -min interval. The first three experiments were each separated by 1 week, with the fourth occurring 6 weeks later.

polarity reversal, we conducted another experiment one week later with the anode placed initially on the right and then, after a break, on the left. We observed the same pattern as before; performance in block 1 was at $50 \%$, and then significantly increased to $70 \%$ in block $2, t(19)=2.2, p<.05$. In a third block conducted after another 15-min break, we reran the experiment without any stimulation to check for practice effects. As can be seen, performance dropped back down to 50\%. In Experiment 3, we conducted two blocks with the anode remaining on the right mastoid to assess whether the improvement resulted from switching electrode polarity or because it simply takes two blocks of trials before improvement occurs. Performance in block 1 was $60 \%$, which lay within the window of chance, $t(19)=1.5$, $p=.16$, and in fact showed a sharp drop in block $2, t(19)=$ $3.6, p<.01$. In a fourth experiment we looked to corroborate these findings. We first showed that keeping the anode on the same side (this time on the left) for two successive blocks did not move performance significantly beyond 50\%; accuracy was $40 \%$ in block $1, t(19)=1.5, p=.16$, and $55 \%$ in block $2, t(19)=1.0, p=.33$. A further $t$ test showed that this $15 \%$ increase was not statistically significant, $t(19)=$ $1.8, p=.08$. In the next block we reconfirmed the basic effect by showing a significant increase from $50 \%$ to $75 \%$ when the anode was switched to the right, $t(19)=2.9, p<$ .01 . As predicted, accuracy declined to $50 \%$ during a second block of anode right trials, $t(19)=2.9, p<.01$. This latter finding was important because it showed that the sharp, and somewhat perplexing, drop observed under the same conditions in Experiment 3 was not replicable, and likely representative of a Type II error. In a final block, we reversed polarity and again saw a significant rise from $50 \%$ to $70 \%$, $t(19)=2.2, p<.05$.

\section{DISCUSSION}

We have shown that the failure to perform a simple facematching task can be temporarily overcome after two, brief, consecutive sessions of subsensory GVS. This confirms a tight coupling between the visual and vestibular systems; impairment to the former can be reduced by altering input to the latter. Though we have shown the effect in only one subject with a limited number of experimental trials, our data give reason to now explore the broader effects of GVS on prosopagnosia.

We note that improvement rested on a different stimulation procedure to that used to treat neglect, in which the anode must always be placed on the side of the intact left hemisphere. Furthermore, there was no instance in which successive blocks of repeated polarity invoked improvement. Rather, improvement only came about after both vestibular nerves were stimulated, irrespective of which side first received positive charge. In recent times, it has become clear that normal face perception involves the operation of both cerebral hemispheres (de Gelder \& Rouw, 2001). It is possible that, via diaschisis, the very extensive, unilateral damage sustained by R.C. interrupted face processing in both hemispheres, which in turn led to the need for bilateral stimulation. Importantly, brain-imaging studies have shown that while vestibular stimulation activates both cerebral hemi- 
spheres, activation is much greater on the side that receives positive stimulation (Dieterich et al., 2003; Fink et al., 2003). If true, then each hemisphere may have needed direct anodal stimulation before the level of activation was sufficient for recovery to occur. It will now be important to determine if this boundary condition results from R.C.'s particular pattern of brain damage or whether it holds for other patients who experience problems perceiving faces. For example, face perception deficits are more commonly associated with damage to the "fusiform face area" in temporal-occipital cortex (see Rhodes et al., 2004), which was spared in R.C. It will be of particular interest to stimulate patients with damage to this region, as this will inform us as to whether the regions directly implicated in face perception must be intact for improvement to occur. From a more practical standpoint, a separate issue will be to establish the long-term safety of repeated stimulation.

\section{ACKNOWLEDGMENTS}

This work was supported by the National Institute of Neurological Disease and Stroke Grant 2 R01 NS 029342-08 A2 and by the Medical Research Service VA Merit Review Awards to William Milberg and Regina McGlinchey. We thank Dr. Kristine Lundgren of the Boston University Harold Goodglass Aphasia Research Center for referring the patient.

\section{REFERENCES}

Bense, S., Stephan, T., Yousry, T.A., Brandt, T., \& Dieterich, M. (2001). Multisensory cortical signal increases and decreases during vestibular galvanic stimulation (fMRI). Journal of Neurophysiology, 85, 886-899.

Bodamer, J. (1947). Die prosop-agnosie. Archiv für Psychiatrie und Nervenkrankenheiten, 179, 6-53.

Coats, A.C. (1972). Limit of normal of the galvanic body-sway test. Annals of Otology, Rhinology and Laryngology, 81, 410-416.

de Gelder, B. \& Rouw, R. (2001). Beyond localisation: A dynamical dual route account of face recognition. Acta Psychologica, 107, 183-207.

De Renzi, E., Perani, D., Carlesimo, G.A., Silveri, M.C., \& Fazio,
F. (1994). Prosopagnosia can be associated with damage confined to the right hemisphere: An MRI and PET study and review of the literature. Neuropsychologia, 32, 893-902.

Dieterich, M., Bense, S., Lutz, S., Drzezga, A., Stephan, T., Bartenstein, P., \& Brandt, T. (2003). Dominance for vestibular cortical function in the non-dominant hemisphere. Cerebral Cortex, 13, 994-1007.

Fink, G.R., Marshall, J.C., Weiss, P., Stephan, T., Grefkes, C., Shah, N.J., Zilles, K., \& Dieterich, M. (2003). Performing allocentric visuo-spatial judgments with induced distortion of the egocentric reference frame: An fMRI study with clinical implications. NeuroImage, 20, 1505-1517.

Kerkhoff, G. (2003). Modulation and rehabilitation of spatial neglect by sensory stimulation. Progress in Brain Research, 142, 257-271.

Kimberley, T.J., Lewis, S.M., Auerbach, E.J., Dorsey, L.L., Lojovich, J.M., \& Carey, J.R. (2004). Electrical stimulation driving functional improvements and cortical changes in subjects with stroke. Experimental Brain Research, 154, 450-460.

McGlinchey-Berroth, R., Milberg, W.P., Verfaellie, M., Alexander, M., \& Kilduff, P. (1993). Semantic processing in the neglected visual field: Evidence from a lexical decision task. Cognitive Neuropsychology, 10, 79-108.

Rhodes, G., Byatt, G., Michie, P.T., \& Puce, A. (2004). Is the fusiform face area specialized for faces, individuation or expert individuation? Journal of Cognitive Neuroscience, 16, 189-203.

Robertson, I.H. \& Murre, J.M.J. (1999). Rehabilitation of brain damage: Brain plasticity and principles of guided recovery. Psychological Bulletin, 125, 544-575.

Rorsman, I., Magnusson, M., \& Johansson, B.B. (1999). Reduction of visuo-spatial neglect with vestibular galvanic stimulation. Scandinavian Journal of Rehabilitation Medicine, 31, $117-124$

Vallar, G., Guariglia, C., \& Rusconi, M.L. (1997). Modulation of the neglect syndrome by sensory stimulation. In P. Thier \& H.O. Karnath (Eds.), Parietal lobe contributions to orientation in 3D space. Heidelberg: Springer Verlag.

Volpe, B.T., Krebs, H.I., Hogan, N., Edelstein, O.L., Diels, C., \& Aisen, M. (2000). A novel approach to stroke rehabilitation: Robot-aided sensorimotor stimulation. Neurology, 54, 1938-1944.

Wilkinson, D., Ko, P., Kilduff, P., McGlinchey, R., \& Milberg, W. (2005). A case of prosopagnosia without object agnosia. Submitted. 